\title{
SISTEM INFORMASI GEOGRAFI UNTUK ANALISIS POTENSI SUMBER DAYA LAHAN PESISIR KEPULAUAN PADAIDO KABUPATEN BIAK NUMFOR, PAPUA
}

\author{
Rosalina G. Mandowen*¹, Rinto H. Mambrasar ${ }^{2}$ \\ ${ }^{1}$ Program Studi Sistem Informasi FMIPA, Universitas Cenderawasih Jayapura \\ ${ }^{2}$ Biologi FMIPA, Universitas Cenderawasih Jayapura \\ ${ }^{1}$ mandowenrosa@gmail.com, ${ }^{2}$ mambrasar.rinto@gmail.com \\ *Penulis Korespondensi
}

(Naskah masuk: 13 Mei 2020, diterima untuk diterbitkan: 18 Oktober 2021)

\begin{abstract}
Abstrak
Sistem Informasi Geografi (SIG) dengan layanan informasi pengelolaan lahan yang cocok sehingga lahan akan bernilai ekonomi, oleh karenanya penelitian ini membahas pemetaan dan pengkajian potensi sumber daya lahan pesisir dalam mendukung usaha budidaya, pariwisata, konservasi, dan daerah tangkapan ikan yang berkelanjutan. Metode penelitian secara deskriptif memakai pendekatan survei untuk pengamatan wilayah penelitian dan pengumpulan data sekunder serta pendekatan analisis spasial untuk parameter dan kriteria kesesuaian lahan. Teknik pengolahan dan analisis data ini menggunakan software SIG yakni ArcGIS 10.1 dengan model skoring dan overlay. Hasil penelitian dengan studi kasus Kepulauan Padaido ini dapat disimpulkan bahwa saat ini dengan adanya SIG yang dibangun, Pemerintah Daerah Biak Numfor sudah dapat mengolah lahan pesisir untuk dimanfaatkan sesuai dengan potensi lahan yang seharusnya, seperti potensi lahan untuk usaha budidaya rumput laut seluas 13.269,41 ha atau 94\%, untuk budidaya teripang seluas $7.069,91$ ha atau $83 \%$, sebagai aktifitas pariwisata pesisir seluas 7.778,45 ha atau $86 \%$, sebagai kegiatan konservasi seluas 2.957,54 ha atau 163\%, untuk daerah tangkapan ikan karang seluas 2.078,92 ha atau 80\%, dan sebagai daerah tangkapan ikan pelagis $1.585,61$ ha atau $87 \%$.
\end{abstract}

Kata kunci: SIG dan ESDA, sumber daya pesisir, padaido

\section{GEOGRAPHIC INFORMATION SYSTEM FOR ANALYSIS OF COASTAL LAND POTENTIAL RESOURCES PADAIDO ISLANDS BIAK NUMFOR REGENCY, PAPUA}

\begin{abstract}
Geographic Information System (GIS) with suitable land management information services so that the land will be of economic value, therefore this study discusses the mapping and assessment of the potential of coastal land resources in supporting sustainable aquaculture, tourism, conservation, and fishing grounds. The descriptive research method uses a survey approach for observation of research areas and secondary data collection as well as a spatial analysis approach for land suitability parameters and criteria. This data processing and analysis technique uses GIS software namely ArcGIS 10.1 with a scoring and overlay model. The results of the study with the Padaido Islands case study can be concluded that currently with the GIS being built, the Regional Government of Biak Numfor has been able to cultivate coastal land to be used according to the potential of the land that should be, such as the potential land for seaweed cultivation business area of 13,269.41 ha or 94\%, for sea cucumber cultivation covering 7,069.91 ha or 83\%, as coastal tourism activities covering 7,778.45 ha or $86 \%$, as conservation activities covering 2,957.54 ha or 163\%, for reef catchments covering 2,078.92 ha or $80 \%$, and as a pelagic catchment area 1,585.61 ha or $87 \%$.
\end{abstract}

Keywords: GIS and ESDA, coastal resources, padaido

\section{PENDAHULUAN}

Kepulauan Padaido terdiri dari 32 pulau-pulau kecil yang tersebar di bagian Timur Kabupaten Biak Numfor (Bappeda Kabupaten Biak Numfor, 2019). Pulau-pulau ini memiliki potensi sumber daya lahan pesisir yang bernilai ekonomi tinggi seperti rumput laut, teripang, pariwisata, konservasi, dan ikan (Ramadhan, dkk., 2016). Upaya meningkatkan nilai ekonomi sumber daya lahan pesisir tersebut, perlu dirumuskan strategi pengelolaan lahan secara tepat dengan menggunakan teknologi informasi pada 
aspek ekonomi, ekologi, sosial, antarsektor, dan segenap pelaku pembangunan (Susetyo, dkk., 2018).

Pengelolaan sumber daya lahan pesisir berbasis komputer kini sudah banyak dilakukan dengan memakai Sistem Informasi Geografi (SIG). SIG adalah paket perangkat lunak terintegrasi yang dirancang khusus untuk dipakai dengan data geografi yang melakukan serangkaian tugas penanganan data yang komprehensif (Akbar, dkk., 2019).

Pada prinsipnya, dengan aplikasi SIG, kita dapat mengumpulkan data spasial, memasukkannya ke dalam sistem SIG, menyimpan dan melakukan analisis spasial untuk membuat peta, grafik, dan tabel (Marasabessy, dkk., 2018) yang dapat membantu keputusan spasial dengan tujuan untuk meningkatkan pengelolaan sumber daya lahan pesisir. SIG digunakan dalam analisis pemetaan sumber daya lahan pesisir agar menjadi lebih mudah dan praktis (Akmal, dkk., 2017). Adapun 6 model analisis spasial dalam SIG, yaitu menyatakan masalah, memecahkan masalah, pengumpulan data, memilih satu model analisis spasial yang sesuai untuk digunakan, memilih aplikasi SIG yang sesuai, dan penerapan model (Adam, dkk., 2019).

Penelitian terdahulu (Susetyo, dkk., 2018) dengan judul Pembangunan Sistem Informasi Zona Potensi Sumber Daya Kelautan Berbasis HMVC Menggunakan Google Maps API dan JSON. Tujuan penelitian tersebut adalah perancangan SIG Zona potensi Kelautan berbasis Web dengan metode Agile Software Development. Hasil penelitian ini meliputi Web SIG zona potensi kelautan dengan Framework CodeIgniter menggunakan teknologi HMVC dan Google Maps API. Aplikasinya menggunakan format JSON untuk memudahkan pengembang dalam mengembangkan aplikasi ke lintas Platformp.

Penelitian berikutnya (Rauf, dkk., 2018) dengan judul Aplikasi Teknologi Penginderaan Jauh dan SIG dalam Pemantauan Potensi Sumberdaya Pesisir dan Laut membahas tentang pemetaan potensi sumberdaya ekosistem wilayah pesisir dan fasilitas pantai beserta luasannya dengan pendekatan teknologi Penginderaan Jauh dan SIG. Penelitian ini menghasilkan beberapa peta ekosistem, yaitu mangrove (327,22 ha), padang lamun (197,3 ha), terumbu karang (0 ha), tambak (13.792,57 ha) dan fasilitas pantai berupa pelabuhan dan dermaga perikanan sebanyak 7 unit.

Penelitian selanjutnya (Mosriula, 2019) dengan judul Analisis Kesesuaian dan Daya Dukung Lahan serta Strategi Pengembangan Budidaya Rumput Laut. Tujuan penelitian ini adalah menganalisis kesesuaian lahan dan menentukan daya dukung lahan serta merumuskan strategi dan kebijakan pengembangan terhadap budidaya rumput laut. Analisis kesesuaian lahan dan daya dukung lahan digunakan SIG dan untuk analisis strategi dan kebijakan pengembangannya digunakan $A^{\prime} W O T$. Penelitian ini menghasilkan kesesuaian lahan sebesar 1.632,876 ha dengan rincian luasan lahan yang sesuai untuk budidaya rumput laut (1.035,54 ha), yang tidak sesuai $(597,336$ ha), dan untuk daya dukung (40,55 unit).

Perbedaan penelitian ini dengan penelitian Susetyo, dkk., (2018) adalah pada metodenya (Agile Software Development) dan hasilnya itu Web zona potensi kelautan berbasis HMVC menggunakan Google Maps API dan JSON. Kelebihan penelitian Susetyo, dkk., (2018) adalah mempermudah pengembang dalam membangun aplikasi, karena pola $H M V C$-nya terstruktur dan lebih efisien.

Perbedaan berikutnya dengan penelitian Rauf, dkk., (2018) adalah tidak digunakannya penginderaan jauh, tidak dilakukan pemetaan terhadap ekosistem padang lamun dan terumbu karang. Kesamaannya adalah sama-sama melihat fasilitas pantai seperti pelabuhan dan dermaga perikanan.

Perbedaan selanjutnya dengan penelitian Mosriula, (2019) adalah penelitian ini tidak memakai $A^{\prime} W O T$ untuk menganalisis strategi dan kebijakan pengembangan budidaya rumput laut.

Kesamaan dari 3 peneliti sebelumnya dengan penelitian ini ada pada penggunaan aplikasi SIG untuk pemetaan sumber daya lahan pesisir. Sedangkan kelebihan penelitian ini dari 3 peneliti sebelumnya adalah dalam analisis perancangan sistem digunakan Exploratory Spatial Data Analysis (ESDA) yang terdapat pada sofware ArcGIS 10.1.

SIG adalah teknologi sistem informasi yang sedang berkembang pesat saat ini dan sudah banyak digunakan untuk menganalisis dan memetakan sumber daya alam, termasuk di dalamnya melakukan penyajian data tentang potensi sumber daya lahan pesisir berbasis data spasial. Kemampuan SIG memang sangat handal dalam pemetaan sehingga dapat menghasilkan produk berupa peta pendukung sektor pemanfaatan sumber daya lahan pesisir serta dapat digunakan untuk menghitung luas area kawasan pesisir yang telah mengalami rusak dan juga dapat membuat strategi untuk penangganannya.

Pemanfaatan SIG untuk pemetaan potensi sumber daya lahan pesisir di Kepulauan Padaido belum banyak dilakukan. Hal ini menjadi dasar penelitian ini dengan tujuan untuk memetakan dan mengkaji potensi sumber daya lahan pesisir dalam mendukung usaha budidaya, jasa pariwisata, konservasi, dan daerah tangkapan ikan di Kepulauan Padaido untuk pemantauan yang berkelanjutan. Hasil akhir tiap peta di overlay untuk mendapat luasan lahan yang sesuai dan peta yang merupakan generalisasi dari masing-masing peta yang dapat dijadikan acuan bagi Pemerintah Daerah Kabupaten Biak Numfor sebagai pengambil kebijakan.

\section{METODE PENELITIAN}

Penelitian ini dilakukan di Kepulauan Padaido Kabupaten Biak Numfor, Papua (Gambar 1). Kepulauan Padaido secara geografi berada di Laut 
Pasifik yang terletak di bagian Timur Pulau Biak pada titik koordinat $01^{\circ} 07^{\prime} 00^{\prime \prime}-1^{\circ} 22^{\prime} 00^{\prime \prime}$ LS dan $136^{\circ} 10^{\prime} 00^{\prime \prime}-136^{\circ} 46^{\prime} 00^{\prime \prime}$ BT dengan luas wilayah sebesar 183,125 ha (Bappeda Kabupaten Biak Numfor, 2019).

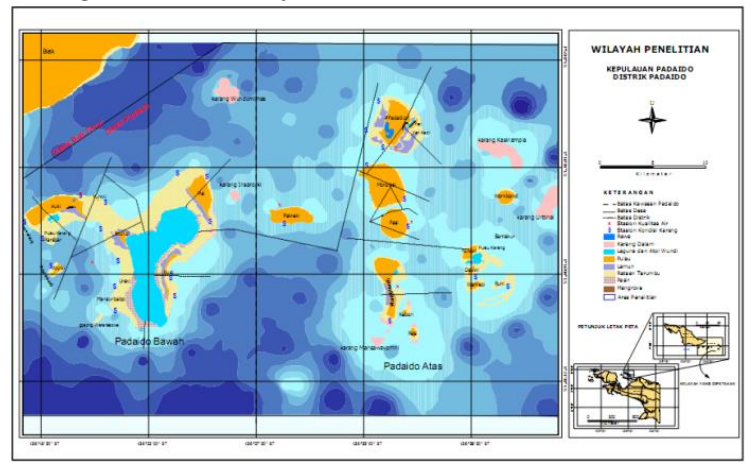

Gambar 1. Wilayah Penelitian Kepulauan Padaido Kabupaten Biak Numfor, Papua

Metode yang digunakan dalam penelitian ini adalah metode deskriptif memakai 2 pendekatan, yaitu: 1) pendekatan survei untuk mengamati wilayah studi dan pengumpulan data sekunder berupa data spasial dan non-spasial dan 2) pendekatan analisis spasial untuk parameter dan kriteria kesesuaian lahan (abiotik, biotik, sosek, sosbud, dan pemakaian lahan). Teknik pengolahan dan analisis data menggunakan SIG, yakni software aplikasi ArcGIS 10.1 (ESRI, 2016) dengan teknik skoring dan overlay yang berbasis pada data vektor (Sukuryadi \& Ali, 2015).

Data vektor dikonversi dalam bentuk raster agar bisa dikalkulasi dengan teknik skor dan bobot. Teknik skoring adalah bagian skor dan bobot pada data raster, yang didalamnya ada proses matematika sesuai parameter tiap kondisi. Teknik overlay adalah penggabungan 2 lapisan untuk membuat kelas fitur keluaran baru yang berisi informasi dari 2 input tersebut (Price, 2015). Teknik overlay tiap peta sumber daya lahan pesisir yang dibuat dilakukan overlay menurut skor dan bobot masing-masing peta yang dihasilkan dalam pemanfaatan lahan pesisir. Data vektor menggunakan lokasi $\mathrm{x}-\mathrm{y}$ untuk menyimpan informasi berupa titik, garis, dan polygon yang dimuat dalam shapefile yang dirancang dan diatur oleh ESRI, dengan maksud agar kerjanya bergantian untuk mengkomunikasikan data antara ESRI dan produk perangkat lunak dan analisis SIG (Ahmed, dkk., 2018).

Analisis dilakukan dengan menggunakan tool yang ada pada software ArcGIS 10.1. Setelah data terformat dan dapat diintegrasikan ke dalam basis data $A r c G I S$ 10.1, dilanjutkan dengan analisis ESDA melalui ExplorData. Tahapan analisis ESDA tinggal mengikuti langkah-langkah yang ada di dalam ArcGIS 10.1. Analisis ESDA digunakan untuk membuat ringkasan nilai dari suatu seri data atau data spasial dalam membuat ringkasan dari atribut tabel atau nilai grid. Selain itu ESDA juga digunakan untuk mendeskripsikan variabilitas spasial suatu peta. Peta dalam hal ini adalah peta budidaya rumput laut dan teripang, jasa pariwisata, konservasi, serta peta daerah tangkapan ikan karang dan ikan pelagis.

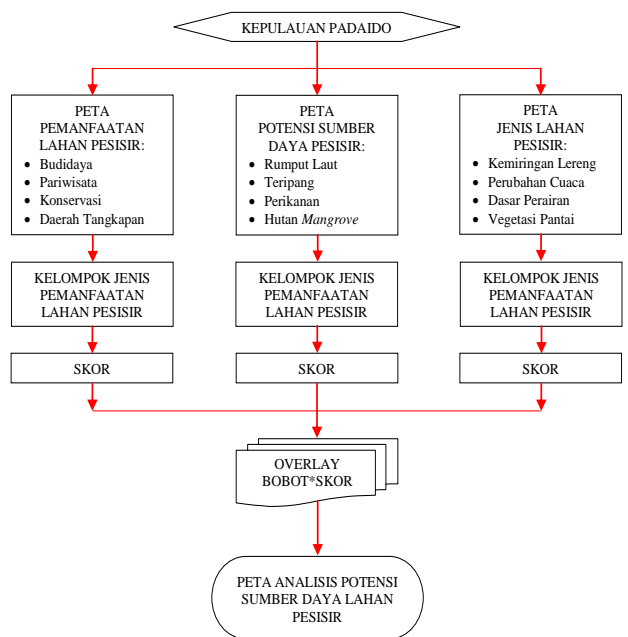

Gambar 2. Tahap-tahap dalam Pengolahan Data

Analisis keruangan diartikan sebagai sekumpulan cara yang bisa dipakai untuk memproses data dalam SIG. Untuk menetapkan penilaian dan ukuran atau variabel tentu mengarah ke peneliti-peneliti sebelumnya yang sudah dilakukan oleh Fauzi, dkk., (2009); Kusuma \& Handayani (2015). Penilaian, yang dipakai untuk menganalisis penentuan keruangan, yaitu penilaian 
umum dan ukurannya masih bersifat sementara. Untuk analisis spasial digunakan formula matematis (Fauzi, dkk., 2009):

$\mathrm{K}(\mathrm{x})=\mathrm{k}($ tak hidup $)+\mathrm{k}($ hidup $)+\mathrm{k}($ sosek $)+\mathrm{f}(\mathrm{RPL})$ dimana:

$\mathrm{K}(\mathrm{x})=$ Kemampuan wilayah dalam kembangkan usaha $\mathrm{x}$

Daya dukung lahan untuk usaha budidaya dihitung dengan formula (Fauzi, dkk., 2009):

$\mathrm{KB}=\mathrm{T}(\mathrm{E})+\mathrm{SD}(<3)+\mathrm{S}(<2000)+\mathrm{P}(<4000)+\mathrm{PL}(\mathrm{r}, \mathrm{b})$ $+\mathrm{PP}(\mathrm{n})+\mathrm{J}(<2000)+\mathrm{RPL}(\mathrm{B})$

dimana: KB (Kapasitas Budidaya), T (ciri Tanah) E (Entisol), SD (Sisi Datar < 3\%), S (Sungai < 2000 m), P (Pesisir < 4000 m), PL (Pemakaian Lahan), r (rawa), b (belukar), PP (Pencaharian Penduduk), $\mathrm{n}$ (nelayan), J (Jalan < 2000 m), RPL (Rencana Pakai Lahan), B (Budidaya).

Kesesuaian lahan untuk rekreasi pantai digunakan persamaan (Kusuma \& Handayani, 2015):

$$
\begin{array}{r}
\mathrm{KR}=\mathrm{P}(\mathrm{p})+\mathrm{K}(\mathrm{c})+\mathrm{D}(<5)+\mathrm{V}(\mathrm{k}, \mathrm{cp})+\mathrm{PL}(\mathrm{lt})+\mathrm{PP}(\mathrm{n}, \mathrm{p}) \\
+\mathrm{J}(<500)+\mathrm{S}(\mathrm{at}, \mathrm{p})+\mathrm{RPL}(\mathrm{R})
\end{array}
$$

dimana: KR (Kapasitas Rekreasi), P (ciri Pantai), K (Kejernihan air), c (cerah), D (Dalamnya air $<5 \mathrm{~m}$ ), V (Vegetasi), k (kelapa), cp (cemara pantai), PL (Pemakaian Lahan), lt (lahan terbuka), PP (Pencaharian Penduduk), n (nelayan), p (penjual), J (Jalan < $500 \mathrm{~m}$ ), S (Sarana), at (air tawar), p (penginapan), RPL (Rencana Pakai Lahan), R (Rekreasi).

Kesesuaian lahan untuk kawasan konservasi dibuat dengan rumus (Kusuma \& Handayani, 2015):

$$
\mathrm{KK}=\mathrm{T}(\mathrm{E})+\mathrm{V}(\mathrm{c}, \mathrm{m})+\mathrm{PL}(\mathrm{h})+\mathrm{RPL}(\mathrm{K})
$$

dimana: KK (Kapasitas Konservasi), T (ciri Tanah), E (Entisol), V (Vegetasi), c (cemara), m (mangrove), PL (Pemakaian Lahan), h (hutan), RPL (Rencana Pakai Lahan), K (Konservasi).

Analisis potensi sumber daya lahan pesisir dilakukan dengan 5 cara yang sama, yaitu: 1) penetapan persyaratan, bobot dan skor; 2) hitung nilai peruntukan lahan (bobot*skor/total nilai bobotskor*100); 3) pembagian 3 kelas lahan (Sesuai/S1 skor 3, Sesuai Bersyarat/S2 skor 2, dan Tidak Sesuai/N skor 1); 4) membanding nilai lahan dengan nilai kelas lahan, dan 5) penyajian grafis berupa peta.

Klasifikasi tingkat kesesuaian lahan berdasarkan jumlah perkalian bobot dengan skor

\begin{tabular}{|c|c|c|c|}
\hline \multicolumn{3}{|c|}{ Kelas Nilai Untuk } & \multirow{2}{*}{$\begin{array}{c}\text { Kelas } \\
\text { Kesesuaian } \\
\text { Lahan }\end{array}$} \\
\hline Budidaya & Pariwisata & Konservasi & \\
\hline $125-185$ & $105-155$ & $90-105$ & Sesuai (S1) \\
\hline $65-125$ & $55-105$ & $40-90$ & $\begin{array}{l}\text { Sesuai Bersyarat } \\
\text { (S2) }\end{array}$ \\
\hline$<65$ & $<55$ & $<40$ & Tidak Sesuai (N) \\
\hline
\end{tabular}
(bobot*skor) untuk budidaya, pariwisata, dan konservasi disajikan dalam Tabel 1.

\section{HASIL DAN PEMBAHASAN}

Hasil observasi potensi sumber daya lahan pesisir Kepulauan Padaido dapat dibedakan menjadi
3 tipe, yaitu: (1) wilayah daratan pulau sebagai tempat tinggal, berkebun, dan selebihnya semak belukar, perkebunan kelapa, dan hutan primer dan sekunder, (2) daratan pantai yang mengalami 2 kali pasang surut dalam sehari, dan (3) wilayah perairan laut dalam sebagai tempat menangkap ikan yang hidup dipermukaan maupun di dasar laut, juga untuk lalulintas pelayaran bagi kapal dan perahu.

Analisis potensi sumber daya lahan pesisir di yang dibuat seluruhnya dilandaskan dari masingmasing parameter biofisik yang tersedia. Hasil analisis spasial dengan pendekatan SIG pada masing-masing peruntukan kesesuaian lahan dapat dilihat pada Tabel 2 .

Tabel 2. Luas Lahan dalam Hektar (ha) dari Setiap Peruntukan

\begin{tabular}{lrrr}
\hline Peruntukan & \multicolumn{1}{c}{$\begin{array}{c}\text { Sesuai } \\
\text { (S1) }\end{array}$} & \multicolumn{1}{c}{$\begin{array}{c}\text { Sesuai } \\
\text { Bersyarat (S2) }\end{array}$} & \multicolumn{1}{c}{$\begin{array}{c}\text { Tidak } \\
\text { Sesuai (N) }\end{array}$} \\
\hline Rumput laut & $13.269,41$ & 79,59 & 34,28 \\
Teripang & $7.069,91$ & $5.480,02$ & 798,99 \\
Pariwisata & $7.778,45$ & $2.270,78$ & $1.329,10$ \\
Konservasi & $2.957,54$ & $4.124,25$ & 895,74 \\
Ikan karang & $2.078,92$ & 958,896 & 654,99 \\
Ikan pelagis & $1.585,61$ & $1.123,20$ & 983,28 \\
\hline
\end{tabular}

Tabel 2 memperlihatkan 6 peruntukan dengan luas yang berbeda-beda.Untuk kelas sesuai (S1) yang terluas rumput laut (13.269,41 ha), kelas sesuai bersyarat (S2) yaitu teripang $(5.480,02 \mathrm{ha})$, dan kelas tidak sesuai $(\mathrm{N})$ adalah rekreasi pantai (1.329,10 ha).

\section{Kesesuaian Lahan Budidaya Rumput Laut}

Umumnya lahan untuk budidaya memiliki syarat fisika, kimia, biologi, teknis, higienis, dan legal. Lahan budidaya dapat diperoleh dengan memperhatikan 4 aspek utama, yaitu aspek ekologi, biologi, tanah, dan aspek sosial.

Nilai masing-masing tingkat kesesuaian lahan untuk budidaya rumput laut diperoleh dari tumpang susun parameter kesesuaian lahan di pesisir

\begin{tabular}{|c|c|c|c|}
\hline \multirow[b]{2}{*}{ Parameter } & \multicolumn{3}{|c|}{ Tingkat Kesesuaian } \\
\hline & $\begin{array}{l}\text { Sesuai } \\
\text { (S1) }\end{array}$ & $\begin{array}{c}\text { Sesuai } \\
\text { Bersyarat } \\
\text { (S2) } \\
\end{array}$ & $\begin{array}{c}\text { Tidak } \\
\text { Sesuai } \\
(\mathbf{N})\end{array}$ \\
\hline Keterlindungan & Baik & Cukup & Kurang \\
\hline Ombak (cm) & $1-10$ & $10-30$ & $30-40$ \\
\hline Gerak Air (cm/det.) & $15-25$ & $\begin{array}{l}10-20 \& \\
30-40\end{array}$ & $<10 \&>40$ \\
\hline Dalamnya air (m) & $3-5$ & $1-3$ & $<1,3 \&>5$ \\
\hline Pangkal perairan & $\begin{array}{l}\text { Karang mati, } \\
\text { Makro alga, } \\
\text { Kersik }\end{array}$ & Kersik & $\begin{array}{l}\text { Kersik, } \\
\text { Tanah lunak }\end{array}$ \\
\hline Salinitas (ppm) & $32-34$ & $30-32$ & $<30 \&>34$ \\
\hline Suhu $\left({ }^{\circ} \mathrm{C}\right)$ & $24-30$ & $20-24$ & $<20 \&>30$ \\
\hline $\mathrm{pH}$ & $7,8-8,2$ & $7,3-7,8$ & $<7,3 \&>8,2$ \\
\hline Kecerahan $(\mathrm{cm})$ & $60-110$ & $30-60$ & $<30$ \\
\hline Kesuburan air & Baik & Cukup & Kurang \\
\hline Ketersediaan benih & Berlimpah & Cukup & Rendah \\
\hline
\end{tabular}
Kepulauan Padaido yang ditampilkan dalam Tabel 3.

Tabel 3. Matriks Kesesuaian Lahan untuk Budidaya Rumput Laut 


\begin{tabular}{llll} 
Fasilitas penopang & Bagus & Memadai & Minim \\
Kontaminasi & Belum ada & Menengah & Tercemar \\
Ketenangan & Tenang & Lumayan & Minim \\
\hline
\end{tabular}

(sesuai) untuk aktifitas budidaya rumput laut di pesisir Kepulauan Padaido sebesar 13.269,41 ha yang disajikan dalam bentuk peta pada Gambar 3 .

Hasil analisis menggunakan perangkat lunak ArcGIS 10.1 pada kesesuaian lahan yang dipakai

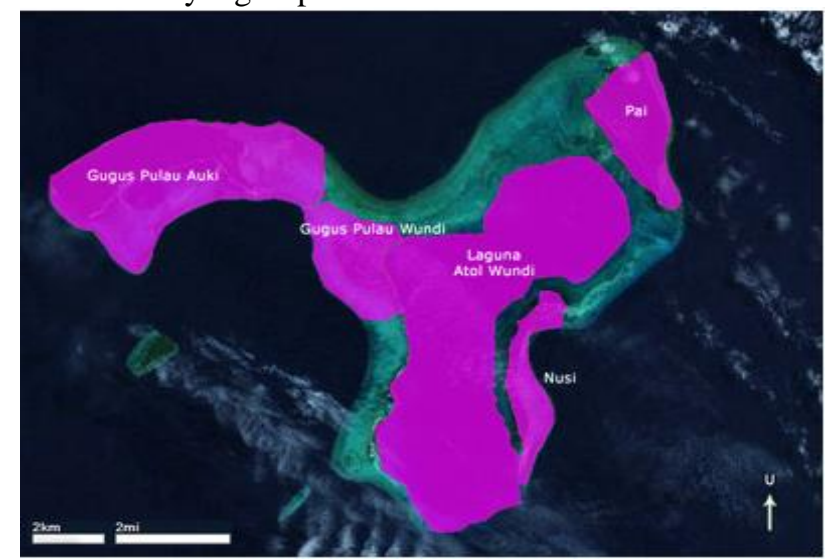

Gambar 3. Peta Kesesuaian Lahan untuk Budidaya Rumput Laut di Kepulauan Padaido

Hasil analisis kesesuaian lahan budidaya rumput laut di Kepulauan Padaido terdiri atas 3 kelas, yaitu kelas sesuai (S1) dengan nilai kesesuaiannya berkisar antara 80-94\% dan tersebar di beberapa pulau diantaranya Pulau Pakreki, Padaidori, Mbromsi, Pasi, Mangguandi, Rasi, Workbondi, Dauwi, Womsowi, dan Pulau Runi, kelas sesuai bersyarat (S2) dengan nilai kesesuaian sebesar 68\% dan hanya ada di rawa Pulau Padaidori, dan kelas tidak sesuai $(\mathrm{N})$ berada di dataran terumbu Pulau atol Wundi, gosong karang, dan perairan laut dalam sekitar Kepulauan Padaido.

\subsection{Kesesuaian Lahan Budidaya Teripang}

Hasil analisis kesesuaian lahan untuk budidaya teripang diperoleh 3 kelas. Pertama, kelas sesuai (S1) ini berada di dataran terumbu Pulau atol Wundi dengan nilai kesesuaian sebesar $83 \%$ dan di rataan terumbu Pulau Mangguandi dengan nilai kesesuaian $82 \%$. Adapun faktor yang mendukung kelas ini adalah lokasinya sangat terlindung, belum adanya pencemaran, keamanaannya baik, dasar perairannya pasir dengan campuran patahan karang, kedalaman air saat surut 0,5-1 m, ketersediaan tumbuhan lamun cukup padat, ketersediaan bibit teripang cukup dekat, kejernihan airnya adalah $100-150 \mathrm{~cm}$, salinitasnya $31-34 \mathrm{ppm}$, suhu airnya $30^{\circ} \mathrm{C}$, oksigen terlarut 6-9 mh/1, pH 8,1-8,6 dan cukup tersedianya sarana dan prasarana penunjang.

Kedua, kelas sesuai bersayat (S2) lahannya tersebar di Pulau atol Wundi, lagon atol Wundi, laguna Auki, Pulau Padaidori, Pulau Mbromsi, Pulau Mangguandi, Pulau Workbondi, dan laguna Dauwi dengan nilai kesesuaiannya berkisar antara 70-77\%. Faktor pendukung kelas ini adalah lokasinya cukup terlindung, masih sedikit tercemar, keamanannya sedang, dasar perairan pasir campur lumpur, kedalaman perairan saat surut $<0,5 \mathrm{~m}$, ketersediaan tumbuhan lamun jarang, ketersediaan bibit teripang jauh, kejernihan perairan $50-100 \mathrm{~cm}$, salinitasnya 27-30 ppm, temperaturnya $26-29^{\circ} \mathrm{C}$, oksigen terlarut 4-6 mh/l, pH 7,5-8,0, sedikitnya sarana penunjang yang tersedia, dan pada saat air pasang tidak terlalu tinggi (sedang).

Ketiga, kelas tidak sesuai (N) lahan ini hanya terdapat di 9 lokasi. Dimana 7 lokasi adalah wilayah pasang surut (pasut) rataan karang, 1 lokasi merupakan tanah genangan air, dan 1 lokasi lagi berbentuk kolam kecil yang dangkal dengan nilai kesesuaian sebesar 69\%. Adapun beberapa faktor yang tidak cukup menunjang lahan ini antara lain keterlindungannya sangat kurang, sudah sangat tercemar, kurang aman, dasar perairannya pasir berlumpur, kedalaman air saat surut $>1 \mathrm{~m}$, tidak adanya tumbuhan air (lamun), ketersediaan sumber benih teripang cukup jauh, kecerahan air $<50 \mathrm{~cm}$, salinitas < $26 \mathrm{ppm}$, suhu air $22-25^{\circ} \mathrm{C}$, oksigen terlarut $<4 \mathrm{mh} / \mathrm{l}, \mathrm{pH}<7,5$, tidak adanya media penopang, dan pada saat air pasang sangat tinggi. Keseluruhannya dapat dilihat pada Tabel 4.

Tabel 4. Matriks Kesesuaian Lahan untuk Budidaya Teripang

\begin{tabular}{|c|c|c|c|}
\hline \multirow[b]{2}{*}{ Parameter } & \multicolumn{3}{|c|}{ Tingkat Kesesuaian } \\
\hline & $\begin{array}{c}\text { Sesuai } \\
\text { (S1) }\end{array}$ & $\begin{array}{c}\text { Sesuai } \\
\text { Bersyarat } \\
(\text { S2) } \\
\end{array}$ & $\begin{array}{c}\text { Tidak } \\
\text { Sesuai } \\
\text { (N) }\end{array}$ \\
\hline Keterlindungan & Sangat & Cukup & Kurang \\
\hline Pencemaran & Tidak ada & Sedikit & Ada \\
\hline Keamanan & Baik & Sedang & Kurang \\
\hline Dasar perairan & $\begin{array}{l}\text { Pasir, } \\
\text { Patahan } \\
\text { karang }\end{array}$ & $\begin{array}{l}\text { Pasir, } \\
\text { Lumpur }\end{array}$ & $\begin{array}{l}\text { Pasir, } \\
\text { Lumpur }\end{array}$ \\
\hline $\begin{array}{l}\text { Kedalaman air } \\
\text { saat surut (m) }\end{array}$ & $0,5-1$ & $<0,5$ & $>1$ \\
\hline $\begin{array}{l}\text { Ketersedian } \\
\text { tumbuhan lamun }\end{array}$ & $\begin{array}{l}\text { Cukup } \\
\text { padat }\end{array}$ & Jarang & $\begin{array}{l}\text { Tidak } \\
\text { ada }\end{array}$ \\
\hline $\begin{array}{l}\text { Adanya bahan } \\
\text { bibit }\end{array}$ & $\begin{array}{l}\text { Cukup } \\
\text { dekat }\end{array}$ & Jauh & $\begin{array}{l}\text { Cukup } \\
\text { jauh }\end{array}$ \\
\hline Jernihnya air $(\mathrm{cm})$ & $100-150$ & $50-100$ & $<50$ \\
\hline Kandungan (ppm) & $31-34$ & $27-30$ & $<26$ \\
\hline
\end{tabular}




\begin{tabular}{llll} 
Temperatur $\left({ }^{\circ} \mathrm{C}\right)$ & 30 & $26-29$ & $22-25$ \\
Gas mencair $(\mathrm{mh} / \mathrm{l})$ & $6-9$ & $4-6$ & $<4$ \\
$\mathrm{pH}$ & $8,1-8,6$ & $7,5-8,0$ & $<7,5$ \\
\hline
\end{tabular}

Berdasarkan hasil overlay maka diperoleh luasan lahan yang digunakan (sesuai) untuk usaha budidaya teripang di pesisir Kepulauan Padaido adalah $7.069,91$ ha yang dibuat dalam bentuk peta

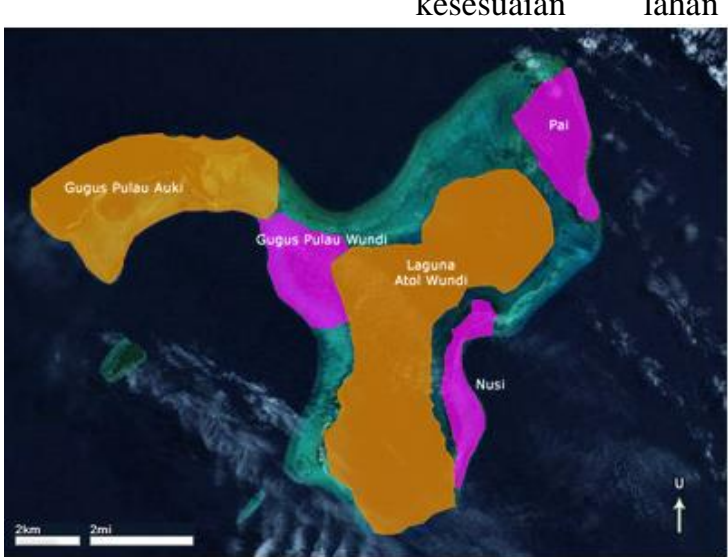

Gambar 4. Peta Kesesuaian Lahan untuk Budidaya Teripang di Kepulauan Padaido

\subsection{Kesesuaian Lahan Pariwisata Pesisir}

Pariwisata pesisir adalah kegiatan yang menggunakan pantai dan tepi laut sebagai tempat yang menarik orang untuk datang berekreasi seperti mengamati keindahan alam pantai. Bentuk-bentuk rekreasi pantai di Kepulauan Padaido antara lain menikmati keindahan pesisir pantai, keindahan alam bawah laut, berjemur, berenang, menyelam, memancing, berlayar, berkemah, mengamati burung pantai, dan jalan-jalan di zona surut yang panjang. Potensi-potensi ini harusnya terus dikembangkan untuk menjadi salah satu ikon pariwisata di Kabupaten Biak Numfor.

Penentuan lahan untuk rekreasi pantai dibuat dengan memperhatikan beberapa syarat, yaitu: 1) kondisi laut yang terlindung dari terumbu karang dan tumbuhan mangrove sebagai pemecah gelombang, 2) terdapatnya area konservasi atau wilayah hijau pesisir seperti adanya tumbuhan mangrove, terumbu karang, dan sumber daya alam pantai lainnya, 3) persoalan pencemaran air (apakah sudah tercemar atau belum) dan kebersihan tepi pantai, dan 4) bentuk pantai, akses transportasi, jalan, pondok wisata, air tawar, listrik, dan telekomunikasi. Berlandaskan pada syarat-syarat yang dikaji tersebut sebagai parameter/variabel yang dibuat menjadi fondasi untuk membuat pola spasial dalam pengembangan semua kegiatan yang terkait dengan aktifitas pariwisata pesisir (berenang dan menikmati keindahan alam pantai) di Kepulauan Padaido.

Kesesuaian lahan yang diperuntukan sebagai kegiatan rekreasi pantai di Kepulauan Padaido dianalisa dengan memakai paramater/variabel dan barometer penilaian terhadap masing-masing wilayah pesisir yang ada.

Ukuran, bobot, dan skor penilaian kesesuaian lahan sebagai tempat rekreasi pantai (pariwisata pesisir) di Kepulauan Padaido dianalisa dengan membandingkan ciri khas lahan dengan prasayarat pemakaian tempat rekreasi pantai seperti keindahan alam bawah laut, keindahan alam pantai, sarana rekreasi pantai, dan transportasi yang tersedia serta keamanan yang ada di Kepulauan Padaido yang ditampilkan dalam Tabel 5.

Tabel 5. Matrik Kesesuaian Lahan untuk Pariwisata Pesisir

\begin{tabular}{|c|c|c|c|}
\hline \multirow[b]{2}{*}{ Parameter } & \multicolumn{3}{|c|}{ Tingkat Kesesuaian } \\
\hline & $\begin{array}{c}\text { Sesuai } \\
\text { (S1) }\end{array}$ & $\begin{array}{c}\text { Sesuai } \\
\text { Bersyarat } \\
\text { (S2) }\end{array}$ & $\begin{array}{c}\text { Tidak } \\
\text { Sesuai } \\
\text { (N) }\end{array}$ \\
\hline Jenis pantai & $\begin{array}{l}\text { Pasir putih, } \\
\text { Karang }\end{array}$ & $\begin{array}{l}\text { Pantai, } \\
\text { Karang }\end{array}$ & $\begin{array}{l}\text { Pasir, } \\
\text { Lumpur }\end{array}$ \\
\hline $\begin{array}{l}\text { Tutupan lahan } \\
\text { pantai }\end{array}$ & $\begin{array}{l}\text { Kelapa, } \\
\text { Semak, } \\
\text { Hutan }\end{array}$ & $\begin{array}{l}\text { Semak, } \\
\text { Kelapa }\end{array}$ & $\begin{array}{l}\text { Hutan, } \\
\text { Semak }\end{array}$ \\
\hline Kejernihan air (m) & $>10$ & $5-10$ & $<5$ \\
\hline Temperatur air $\left({ }^{0} \mathrm{C}\right)$ & $>28$ & $24-28$ & $<24$ \\
\hline Bentuk tubir & $>45^{\circ} \mathrm{C}$ & $<45^{\circ} \mathrm{C}$ & Landai \\
\hline Rugousity & Goa-goa & $\begin{array}{l}\text { Lorong- } \\
\text { lorong }\end{array}$ & Rata \\
\hline Tutupan karang & Tinggi & Sedang & Rendah \\
\hline Jenis live form & $>10$ & $6-9$ & $<6$ \\
\hline Jenis ikan karang & $>120$ & $61-119$ & $<60$ \\
\hline Jenis lamun & $>6$ jenis & 4-5 jenis & $<3$ jenis \\
\hline Jenis mangrove & $>6$ jenis & $4-5$ jenis & $<3$ jenis \\
\hline Estetika & Tinggi & Sedang & Rendah \\
\hline Kemudahan & Tinggi & Sedang & Rendah \\
\hline Keselamatan & Tinggi & Sedang & Rendah \\
\hline Cuaca tenang & $>5$ & $3-5$ & $1-2$ \\
\hline Transportasi & Ada & Sedang & Kurang \\
\hline Air tawar & Ada & Sedang & Kurang \\
\hline Pondok wisata & Ada & Sedang & Kurang \\
\hline Listrik & Ada & Sedang & Kurang \\
\hline Telekomunikasi & Ada & Sedang & Kurang \\
\hline
\end{tabular}

Pada tabel 5 dapat dilihat bahwa untuk analisis dilakukan dengan membandingkan atau memadukan karakteristik lahan dengan persyaratan penggunaan 
lahan sebagai pariwisata pesisir, yaitu kondisi bentang alam dan fasilitas pariwisata yang tersedia.

Hasil analisis spasial kesesuaian lahan pesisir untuk kegiatan rekreasi pantai (pariwisata pesisir) di Kepulauan Padaido diperoleh luasan lahan yang digunakan (sesuai) adalah sebesar 7.778,45 ha yang dibuat dalam bentuk peta kesesuaian lahan pada Gambar 5.

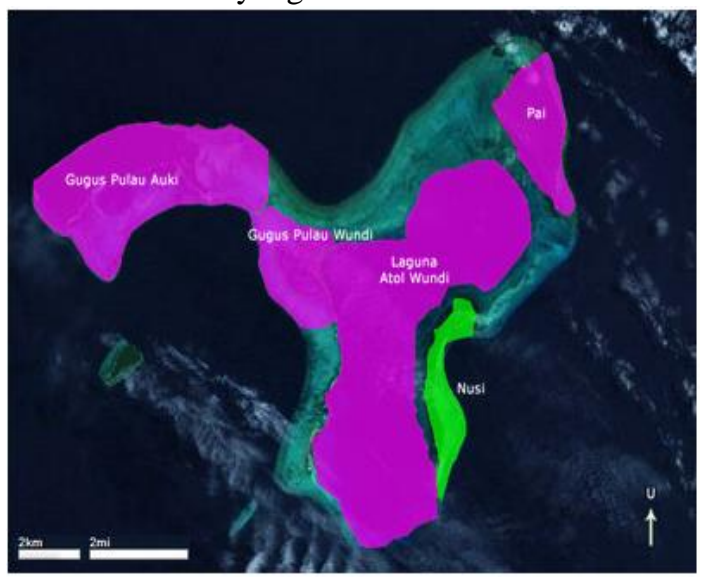

Gambar 5. Peta Kesesuaian Lahan untuk Pariwisata Pesisir di Kepulauan Padaido

Hasil penyelidikan potensi sumber daya lahan pesisir untuk pariwisata pesisir ada 3 kelas. Pertama, kelas sesuai (S1) dengan nilai kesesuaianya berkisar antara $80-86 \%$. Lokasi ini terdapat pada beberapa pulau, yaitu Pulau Auki, Wundi, Pai, dan Pulau Dauwi. Kegiatan pariwisata pesisir yang dapat dinikmati adalah keindahan alam pasir putih, tebing karang, berjemur, berenang, menyelam, berlayar, dan mengamati burung pantai.

Kedua, kelas sesuai bersyarat (S2) memiliki nilai kesesuaian berkisar antara 73-76\%. Lahan ini terletak di Pulau Padaidori dan Pulau Mangguandi. Aktifitas wisata yang bisa dinikmati adalah keindahan alam pulau, berkemah, berlayar, renang, dan jalan-jalan di zona surut yang panjang.

Ketiga, kelas tidak sesuai $(\mathrm{N})$ punya nilai kesesuaian berkisar antara 60-67\%. Lokasi ini berada di Pulau Nusi, Pakreki, Mbromsi, dan Pulau Pasi. Faktor yang kurang mendukung adalah kurangnya transportasi, air tawar, pondok wisata, dan listrik. Kelas ini tidak sesuai karena merupakan laut dalam.

\subsection{Kesesuaian Lahan Kawasan Konservasi}

Isu konservasi kini sudah jadi tugas global dan juga salah satu masalah kebijakan di Papua. Program konservasi di Papua harusnya searah dengan konsep Blue Economy agar dapat membantu industri kelautan dan perikanan secara efektif dan berkelanjutan.

Kawasan konservasi pesisir di Kepulauan Padaido merupakan suatu upaya untuk melindungi, melestarikan, dan memanfaatkan lahan pesisir dan ekosistemnya secara berkelanjutan. Misalnya, kawasan konservasi pesisir dikelola dengan sistem zonasi seperti zonasi perikanan berkelanjutan yang bisa dikelola penduduk dalam usaha budidaya dan penangkapan biota laut yang ramah lingkungan dan zonasi penggunaan dalam aktivitas rekreasis pantai.
Penentuan lokasi yang sesuai untuk kawasan konservasi di Kepulauan Padaido ditentukan dengan menggunakan matriks kesesuaian lahan dengan melakukan pembobotan dan skor pada masingmasing parameter/variabel yang mendukung lahan seperti yang disajikan dalam Tabel 6 .

Tabel 6. Matriks Kesesuaian Lahan untuk Kawasan Konservasi

\begin{tabular}{llll}
\hline & \multicolumn{3}{c}{ Tingkat Kesesuaian } \\
\cline { 2 - 4 } Parameter & \multicolumn{1}{c}{$\begin{array}{c}\text { Sesuai } \\
(\text { S1 })\end{array}$} & \multicolumn{1}{c}{$\begin{array}{c}\text { Sesuai } \\
\text { Bersyarat } \\
\text { (S2) }\end{array}$} & $\begin{array}{c}\text { Tidak } \\
\text { Sesuai }\end{array}$ \\
& & \multicolumn{1}{c}{$(\mathbf{N})$} \\
\hline Tanah & Entisol & Entisol & Non Entisol \\
Vegetasi & Mangrove, & Batu karang, & Kelapa \\
& Cemara & Terumbu karang & \\
Penggunaan & Wisata & Cagar & Permukiman \\
lahan & bahari & alam & \\
Mata & Nelayan & Nelayan, & PNS, \\
pencaharian & & Pedagang & Swasta \\
Zona & Resapan & Resapan & Tidak \\
resapan & Air & air & berarti \\
Air & utama & tambahan & sama sekali \\
RPW & Konservasi & Konservasi & Non \\
& & & konservasi \\
\hline
\end{tabular}

Pada tabel 6 dapat dilihat bahwa untuk analisa dipakai perbandingan dari ciri-ciri lahan dengan syarat pemakaian lahan sebagai kawasan konservasi seperti kondisi bentangan alam dan fasilitas pariwisata yang ada. Untuk parameter vegetasi kelas sesuai terdapat tumbuhan mangrove dan tumbuhan cemara pantai, vegetasi kelas sesuai bersyarat ada batu karang dan terumbu karang, pemakaian lahan kelas sesuai sebagai wisata bahari, penggunaan lahan kelas sesuai bersyarat sebagai cagar alam, untuk zona resapan air pada kelas sesuai sebagai resapan air utama, kelas sesuai bersyarat sebagai zona resapan air tambahan, dan parameter untuk Rencana Pakai Wilayah (RPW) pada kategori kelas sesuai dan kelas sesuai bersyarat yang cocok untuk 
kegiatan konservasi atau jalur hijau pantai. Sedangkan untuk kelas tidak sesuai tidak cocok untuk aktifitas konservasi.

Dari hasil overlay diperoleh luasan lahan yang digunakan dalam kategori kelas sesuai (S1) sebesar 2.957,54 ha dan kategori kelas sesuai bersyarat (S2) adalah 4.124,25 ha untuk kegiatan konservasi atau jalur hijau pantai di lahan pesisir Kepulauan Padaido yang dibuat dalam bentuk peta kesesuaian lahan pada Gambar 6.

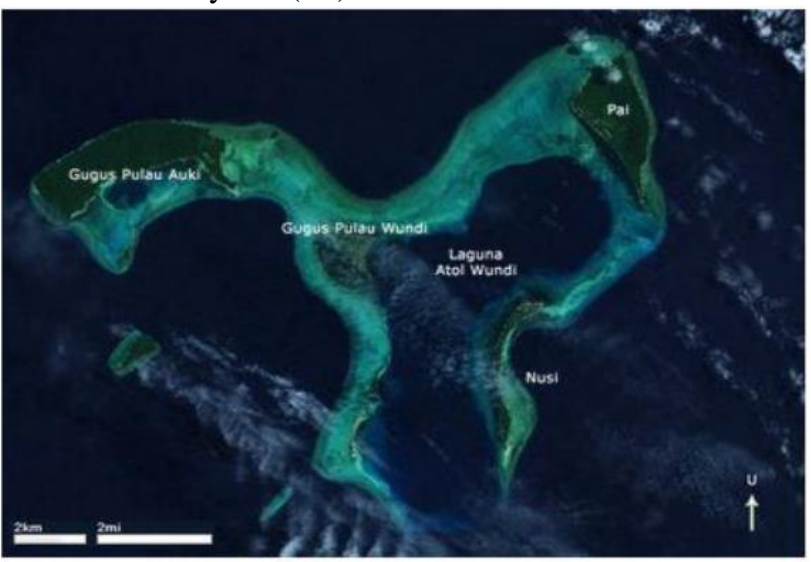

Gambar 6. Peta Kesesuaian Lahan untuk Kawasan Konservasi di Kepulauan Padaido

Hasil analisis potensi sumber daya lahan pesisir sebagai kawasan konservasi atau jalur hijau pantai ada 3 kelas, yaitu kelas sesuai (S1) dengan nilai kesesuaian berkisar antara $87-163 \%$ dan tersebar di beberapa pulau, yaitu Pulau Auki, Mbromsi, Pasi, Pai, Nusi, dan Pulau Wundi yang merupakan wilayah paling sesuai untuk dijadikan sebagai kawasan konservasi. Hasil survei diperoleh vegetasi di pulau-pulau tersebut bervariasi yang didominasi oleh tumbuhan mangrove, terumbu karang, kelapa, dan sebagian tumbuhan cemara pantai. Kelas sesuai bersyarat (S2) mempunyai nilai kesesuaian berkisar antara 65-96\% dan tersebar di beberapa pulau, yaitu Pulau Auki, Pai, Padaidori, Mbromsi, dan Pulau Dauwi. Kelas sesuai bersyarat ini juga cocok untuk kegiatan konservasi pesisir. Kelas tidak sesuai $(\mathrm{N})$ ini hanya ada di Pulau Nusi dengan parameter RPW yang tidak sesuai untuk konservasi.

\subsection{Kesesuaian Lahan Tangkapan Ikan Karang}

Pada ekosistem terumbu karang ada komunitas ikan karang yang hidup. Komunitas ikan karang ini dapat dibedakan menjadi 2 kelompok, yaitu kelompok ikan yang kadang ada di terumbu karang (Patty, dkk., 2015) dan ikan yang bergantung di terumbu karang (Awuy, dkk., 2017) sebagai tempat cari makan, tempat hidup atau kedua-duanya.

Kelas kesesuaian lahan tempat mencari ikan karang ada 3, yaitu kelas sesuai (S1) dengan nilai kesesuaian lahan sebesar $80 \%$ dan terdapat di terumbu karang beberapa pulau antara lain Pulau Wundi, Urev, Mansurbabo, Nukori, Dauwi, Wamsoi, Runi, Workbondi, karang Urbinai, dan karang Kasinampia. Kelas sesuai bersyarat (S2) memiliki nilai $72-76 \%$ terdapat di Pulau Auki, Yumni, Rarsbar, dan Auki. Kelas tidak sesuai (N) punya nilai $64 \%$ terdapat di Pulau Pai, Insarorki, Wundumimas, Padaidori, dan Pulau Yeri.
Kesesuaian lahan sebagai tempat mencari ikan karang di Kepulauan Padaido dianalisis dengan ketentuan bobot dan skor. Parameternya adalah kedalaman, topografi, cuaca, kondisi karang, dan banyaknya ikan karang. Keseluruhannya dapat dilihat pada Tabel 7.

Tabel 7. Matriks Kesesuaian Lahan Tangkapan Ikan Karang

\begin{tabular}{|c|c|c|c|}
\hline \multirow[b]{2}{*}{ Parameter } & \multicolumn{3}{|c|}{ Tingkat Kesesuaian } \\
\hline & $\begin{array}{c}\text { Sesuai } \\
\text { (S1) }\end{array}$ & $\begin{array}{c}\text { Sesuai } \\
\text { Bersyarat } \\
\text { (S2) }\end{array}$ & $\begin{array}{c}\text { Tidak } \\
\text { Sesuai } \\
(\mathbf{N})\end{array}$ \\
\hline Dalamnya air (m) & $>7$ & $4-7$ & $<4$ \\
\hline Jarak dari dasar air & Terjal & $\begin{array}{l}\text { Menurun-- } \\
\text { Terjal }\end{array}$ & Landai \\
\hline Jernihnya air (m) & $>10$ & $5-10$ & $<5$ \\
\hline Berubahnya udara & Jarang & Sedang & Sering \\
\hline $\begin{array}{l}\text { Keadaan terumbu } \\
\text { Karang }\end{array}$ & Baik & Sedang & Buruk \\
\hline $\begin{array}{l}\text { Kotornya air } \\
\text { Banyaknya ikan } \\
\text { karang (ind./350 } \mathrm{m}^{2} \text { ) }\end{array}$ & $\begin{array}{l}\text { Tidak ada } \\
>200\end{array}$ & $\begin{array}{l}\text { Sedikit } \\
100-200\end{array}$ & $\begin{array}{l}\text { Ada } \\
<100\end{array}$ \\
\hline
\end{tabular}

Tabel 7 menjelaskan hasil analisa lahan tangkapan ikan karang yang dilihat dari 7 paramater, diantaranya adalah kedalaman perairan yang sesuai adalah $>7 \mathrm{~m}$, sesuai bersyarat antara 4-7 $\mathrm{m}$, dan tidak sesuai $<4 \mathrm{~m}$, kejernihan perairan $>10 \mathrm{~m}$, sesuai bersyarat 5-10 m, dan tidak sesuai $<5 \mathrm{~m}$, perubahan cuaca kelas sesuai jarang terjadi, kelas sesuai bersyarat kadang terjadi, dan kelas tidak sesuai cuacanya sering terjadi. Untuk kondisi terumbu karang pada kelas sesuai adalah baik, kelas sesuai bersyarat sedang, dan kelas tidak sesuai buruk. Sedangkan kelimpahan ikan target kelas sesuai adalah > 200 ind./350 $\mathrm{m}^{2}$, kelas sesuai bersyarat $100-200$ ind. $/ 350 \mathrm{~m}^{2}$, dan kelas tidak sesuai $<100$ ind. $/ 350 \mathrm{~m}^{2}$. Faktor lainnya adalah pencemaran, ada yang belum tercemar, sedikit, dan banyak. 
Sebanyak 20 lahan terumbu karang yang diselidiki sebagai tempat mencari ikan karang. Lahan-lahan tersebut adalah karang dangkal, karang dalam, dan karang kosong. Adapun jenis ikan karang yang sering ditangkap nelayan, yaitu ikan kerapu, kakap, kaka tua, baronang, dan ikan karang lainnya.
Hasil analisis spasial kesesuaian lahan untuk daerah tangkapan ikan karang di Kepulauan Padaido diperoleh luasan lahan yang sesuai (S1) sebesar 2.078,92 ha dan yang sesuai bersyarat (S2) sekitar 958,896 ha yang dibuat dalam bentuk peta kesesuaian lahan pada Gambar 7.

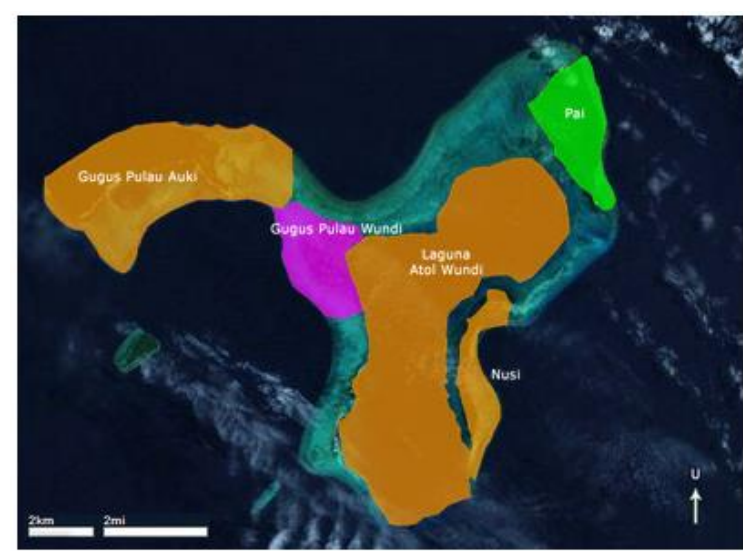

Gambar 7. Peta Kesesuaian Lahan Tangkapan Ikan Karang di Kepulauan Padaido

\subsection{Kesesuaian Lahan Tangkapan Ikan Pelagis}

Ikan pelagis adalah ikan yang hidupnya berkelompok di kedalaman laut yang masih bisa dicapai sinar matahari. Jenis ikan pelagis ini dibedakan berdasarkan ukuran, yaitu ikan pelagis besar seperti ikan cekalang, tenggiri, layar, pedang, marlin, cucut, dan jenis-jenis ikan tuna. Sedangkan ikan pelagis kecil seperti ikan kembung, tongkol, mumar, selar, japuh,tembang, dan ikan puri.

Kedepannya potensi pengembangan ikan pelagis baikukuran besar dan kecil di Kepulauan Padaido sangat berpeluang sebagai sumber mata pencaharian masyarakat nelayan karena cara penangkapan yang dilakukan oleh masyarakat nelayan saat ini terlihat cukup rama lingkungan sehingga efesien dan berkelanjutan. Misalnya, di Pulau Wundi, Pakreki, dan Dauwi menjadi lokasi penangkapan jenis-jenis ikan pelagis seperti ikan cakalang ekor kuning, tenggiri, layar, tuna, kembung, tongkol, dan momar yang sangat melimpah. Begitu juga banyak ditemukan di pasar tradisional Bosnik Distrik Biak Timur, banyak ikan pelagis yang dipasarkan seperti ikan tuna, tenggiri, kembung, momar, dan cekalang.

Hasil analisis kesesuaian lahan untuk daerah tangkapan ikan pelagis di perairan Kepulauan Padaido yang dikelilingi oleh kumpulan pulau-pulau kecil dan perairan laut lagoon hanya diperoleh 1 kelas, yaitu kelas sesuai (S1). Kelas ini memiliki nilai kesesuaian berkisar dari $83-87 \%$ dan hanya terdapat di Pulau karang Wundi. Pulau karang Wundi sesuai sebagai tempat mencari dan menangkap ikan pelagis besar dan untuk ikan pelagis kecil lokasi penangkapannya lebih ke bagian kawasan laut terumbu karang Pulau Wundi yang berbentuk lingkaran.

Umumnya tempat untuk mencari dan menangkap ikan pelagis ukuran besar dan kecil adalah di kawasan laut dalam yang dikelilingi oleh kumpulan pulau-pulau kecil di Kepulauan Padaido. Faktor penunjang wilayah mencari ikan pelagis adalah parameter oseanografi perairan seperti suhu, salinitas, kedalaman, oksigen, kejernihan, cuaca, dan pencemaran seperti yang disajikan dalam Tabel 8 .

\begin{tabular}{llll}
\multicolumn{1}{c}{ Tabel 8. Matriks Kesesuaian Lahan Tangkapan Ikan Pelagis } \\
\cline { 2 - 4 } \multicolumn{1}{c}{ Parameter } & \multicolumn{3}{c}{ Tingkat Kesesuaia } \\
& \multicolumn{1}{c}{ Sesuai } & $\begin{array}{c}\text { Sesuai } \\
\text { Bersyarat } \\
(\text { S2 })\end{array}$ & $\begin{array}{c}\text { Tidak } \\
\text { Sesuai } \\
(\mathbf{N})\end{array}$ \\
\hline Suhu air laut $\left({ }^{0} \mathrm{C}\right)$ & $>29$ & $20-29$ & $<20$ \\
Salinitas $(\mathrm{ppt})$ & $>30$ & $25-30$ & $<25$ \\
Kedalaman $(\mathrm{m})$ & $>100$ & $50-100$ & $<50$ \\
Kebutuhan O2 $(\mathrm{mg} / \mathrm{l})$ & $>4$ & $2-4$. & $<2$ \\
Jernihnya perairan $(\mathrm{m})$ & $>30$ & $20-30$ & $<20$ \\
Perubahan cuaca & Jarang & Sedang & Sering \\
Pencemaran air & Tidak ada & Sedikit & Ada \\
\hline
\end{tabular}

Tabel 8 menjelaskan bahwa hasil analisis kawasan pesisir dari parameter suhu air laut yang sesuai adalah $>29^{\circ} \mathrm{C}$, sesuai bersyarat berkisar antara $20-29^{\circ} \mathrm{C}$, dan tidak sesuai $<20^{\circ} \mathrm{C}$, untuk salinitas yang sesuai > $30 \mathrm{ppt}$, sesuai bersyarat antara 25-30 ppt, dan tidak sesuai $<20 \mathrm{ppt}$, kedalama perairan yang sesuai adalah $>100 \mathrm{~m}$, sesuai bersyarat berkisar antara 50-100 m, dan tidak sesuai < $50 \mathrm{~m}$, oksigen terlarut yang sesuai adalah > $4 \mathrm{mg} / \mathrm{l}$, sesuai bersyarat 2-4 mg/l, dan tidak sesuai < $2 \mathrm{mg} / \mathrm{l}$, kejernihan perairan berkisar antara 20-30 m, dan perubahan cuaca jarang terjadi pada kelas sesuai, kadang (sedang) terjadi pada kelas sesuai bersyarat, dan kelas tidak sesuai itu sering sekali terjadi perubahan cuaca seperti hujan deras, angin, dan gelombang tinggi.

Cuaca merupakan faktor yang kurang mendukung masyarakat nelayan di Kepulauan 
Padaido, karena cuaca yang menentukan berapa lama kegiatan penangkapan ikan akan dilakukan. Apabila cuaca bagus, nelayan melakukan penangkapan selama 1 hari dan sebaliknya apabila cuaca di sekitar Kepulauan Padaido sedang tidak baik nelayan tidak melakukan kegiatan penangkapan ikan karena keterbatasan armada penangkapan serta sarana dan prasarana lainnya.
Dari hasil overlay diperoleh luasan lahan untuk daerah tangkapan ikan pelagis di Kepulauan Padaido yang sesuai (S1) adalah $1.585,61$ ha dan sesuai bersyarat (S2) 1.123,20 ha yang dibuat dalam bentuk peta kesesuaian lahan pada Gambar 8.

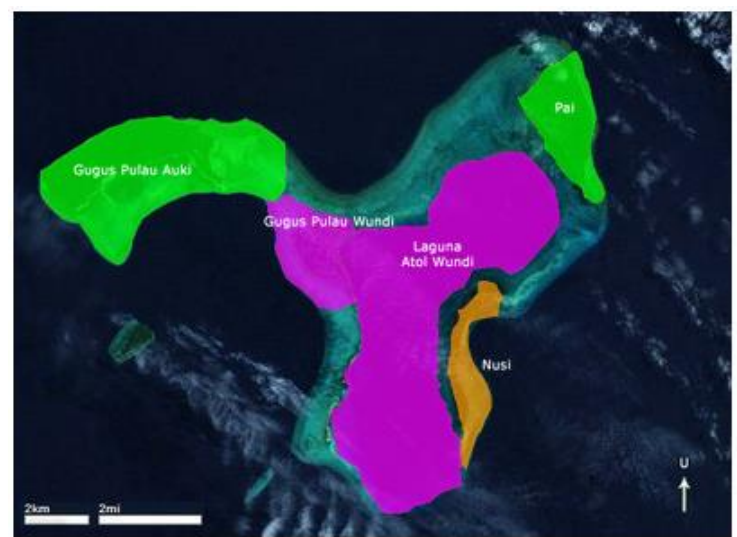

Gambar 8. Peta Kesesesuaian Lahan Tangkapan Ikan Pelagis di Kepulauan Padaido

\section{KESIMPULAN}

Berdasarkan kegiatan penelitian yang telah dilakukan pengolahan dan analisis data potensi lahan pesisir dapat ditarik kesimpulan sebagai berikut:

1. Dengan adanya SIG penelitian ini berhasil merancang dan membangun 6 peta potensi sumber daya lahan pesisir dengan luasan lahan yang berbeda-beda.

2. Data dan peta ini sudah bisa digunakan Pemerintah Daerah Kabupaten Biak Numfor sesuai dengan potensi lahan yang seharusnya seperti usaha budidaya rumput laut (13.269,41 ha), usaha budidaya teripang (7.069,91 ha), kegiatan pariwisata pesisir $(7.778,45$ ha), kegiatan konservasi (2.957,54 ha), untuk daerah tangkapan ikan karang (2.078,92 ha), dan daerah tangkapan ikan pelagis (1.585,61 ha).

\section{DAFTAR PUSTAKA}

ADAM, S.S., RINDARJONO, M.G. \& KARYANTO, P., 2019. Sistem Informasi Geografi untuk Zonasi Kerentanan Kebakaran Lahan dan Hutan di Kecamatan Malifut, Halmahera Utara. Jurnal Teknologi Informasi dan Ilmu Komputer(JTIIK), 6(5), pp. 559-566. DOI: http://dx.doi.org/10.25126/jtiik.201961674

AHMED, Z.U., KRUPNIK, T.J. \& KAMAL, M., 2018. Introduction to basic GIS and spatial analysis using QGIS: Application in Bangladesh. Dhaka, Bangladesh: CSISA, CIMMYT, p. 40.
AKBAR, L.O.J., Yusuf, D. \& Kasim, M., 2019. Analisis Potensi Wisata Bahari Berbasis Sistem Informasi Geografis di Pantai Langala Provinsi Gorontalo. Jambura Geoscience Review (JGEOSREV), 1(1), pp. 30-39.

DOI: https://doi.org/10.34312/jgeosrev.v1i1.2036

AKMAL, S.G., FAHRUDIN, A. \& AGUS, S.B., 2017. Distribusi Spasial Kelimpahan Sumberdaya Ikan di Perairan Selat Sunda. Jurnal Pengelolaan Perikanan Tropis, 1(1), pp. 25-31. DOI: https://doi.org/10.2924/jppt.v1i1.20150

AWUY, G., RONDONUWU, A.B. \& KAMBEY, A.D., 2017. Komunitas Ikan Karang Pada Terumbu Buatan di Perairan Kareko Kecamatan Lembeh Utara Kota Bitung Provinsi Sulawesi Utara. Jurnal Ilmiah Platax, 5(2), pp. 145-154. DOI: https://doi.org10.35800/jip.5.2.2017.15811

BADAN PERENCANAAN PEMBANGUNAN DAERAH (BAPPEDA) KABUPATEN BIAK NUMFOR, 2019. Dokumen Rencana Pembangunan Jangka Menengah Daerah (RPJMD) 2019-2023 Kabupaten Biak Numfor. Biak Numfor: BAPPEDA, p. 280.

ENVIRONMENTAL SYSTEMS RESEARCH INSTITUTE (ESRI), 2016. The ArcGIS Imagery Book. (C. Brown \& C. Harder, Eds.). California: ESRI Press.

FAUZI, Y., SUSILO, B. \& MAYASARI, Z.M., 2009. Analisis Kesesuaian Lahan Wilayah Pesisir Kota Bengkulu Melalui Perancangan Model Spasial dan Sistem Informasi Geografis (SIG). Jurnal Forum Geografi, 23(2), pp. 101-111. DOI: https://doi.org/10.23917/forgeo.v23i2.5002

KUSUMA, I.J. \& HANDAYANI, H.H., 2015. Studi Klasifikasi Berbasis Objek untuk Kesesuaian 
Tutupan Lahan Tambak, Konservasi, dan Permukiman Kawasan Pesisir (Stusi Kasus: Kecamatan Asemrowo, Krembangan, Pabean Cantikan, dan Semampir, Kota Surabaya). Journal of Geodesy and Geomatics (GEOID), 10(2), pp. 163-170. DOI: http://dx.doi.org/10.12962/j24423998.v1i2.800

MARASABESSY, I., FAHRUDIN, A., IMRAN, Z. \& AGUS, S.B., 2018. Strategi Pengelolaan Berkelanjutan Pesisir dan Laut Pulau Nusa Manu dan Pulau Nusa Leun di Kabupaten Maluku Tengah. Journal of Regional and Rural Development Planning, 2(1), pp. 11-22. DOI: https://doi.org/10.29244/jp2wd.2018.2.1.11-22

MOSRIULA, M., 2019. Analisis Kesesuaian dan Daya Dukung Lahan serta Strategi Pengembangan Budidaya Rumput Laut di Kecamatan Labakkang Kabupaten Pangkep, Indonesia. Akuatikisle: Jurnal Akuakultur, Pesisir dan Pulau-Pulau Kecil, 3(2), pp. 81-90. DOI: https://doi.org/10.29239/j.akuatikisle.3.2.81-90

PRICE, M.H., 2015. Mastering ArcGIS. Seventh Edition. New York: McGraw Hill Education.

RAMADHAN, A., LINDAWATI, \& KURNIASARI, N., 2016. Nilai Ekonomi Ekosistem Terumbu Karang di Kabupaten Wakatobi. Jurnal Sosial Ekonomi Kelautan dan Perikanan, 11(2), pp. 133-146. DOI: http://dx.doi.org/10.15578/jsekp.v11i2.3834

RAUF, A., YUSUF, K., ASMIDAR, KASNIR, M. \& TAJUDDIN, M., 2018. Aplikasi Teknologi Penginderaan Jauh dan Sistem Informasi Geografis dalam Pemantauan Potensi Sumberdaya Pesisir dan Laut di Kabupaten Pangkeb. Journal of Indonesian Tropical Fisheries, 1(1), pp. 11-16. DOI: https://doi.org/10.33096/joint-fish.v1i1.15

SUKURYADI \& ALI, I., 2015. Pemetaan Potensi Sumber Daya Wilayah Pesisir Selatan Kabupaten Lombok Timur dengan Aplikasi Sistem Informasi Geografis. Paedagoria: Jurnal Kajian, Penelitian dan Pengembangan Kependidikan, 11(1), pp. 37-48.

DOI: https://doi.org/10.31764/paedagoria.v6i1.102

SUSETYO, Y.A., SAIAN, P.O.N. \& SOMYA, R., 2018. Pembangunan Sistem Informasi Zona Potensi Sumber Daya Kelautan Kabupaten Gunungkidul Berbasis HMVC Menggunakan Google Maps API dan JSON. Indonesian Journal of Modeling and Computing (ICM), 1(2), pp. 101-107. DOI: https://doi.org/10.24246/j.icm.2018.v1.i2.p101-107

PATTY, W., MANU, G., REPPIE, E. \& DEY, L.N., 2015. Komunitas Ikan Karang pada
Terumbu Buatan Biorock di Perairan Pulau Siladen Kota Manado, Sulawesi Utara. Jurnal Perikanan (Journal of Fisheries Sciences), 17(2), pp. 73-78. DOI: https://doi.org/10.22146/jfs.10364 
Halaman ini sengaja dikosongkan 